\title{
Efficacy and Tolerability of Sufentanil as the sole opioid for treatment of intra- and postoperative pain in patients undergoing Total Abdominal Hysterectomy (TAH)
}

\author{
Y.Leykin ${ }^{1}$, N. Busetto', G. Chersini', A. Laudani ${ }^{2}$ \\ 'Azienda per l'Assistenza Sanitaria n. 5 - Friuli Occidentale, Anesthesia and Intensive Care, Pordenone, Italy. \\ ${ }^{2}$ AOU San Giovanni di Dio e Ruggi d'Aragona, Anesthesia and Intensive Care, Salerno, Italy.
}

\section{Background an aims:}

Optimal perioperative pain management requires both efficacy and a low rate of adverse events (AEs). Sufentanil Sublingual Tablet System (SSTS) is a handheld PCA device that delivers a fixed dose of $15 \mathrm{mcg}$ sufentanil tablets on a PRN basis. Previously, we reported the successful use of SSTS for postoperative pain control after TAH. However, intraoperatively, we used opioids other than sufentanil. Now we assess the analgesic efficacy and tolerability of sufentanil as the sole opioid for treatment of intra- and postoperative pain in patients undergoing $\mathrm{TAH}$.
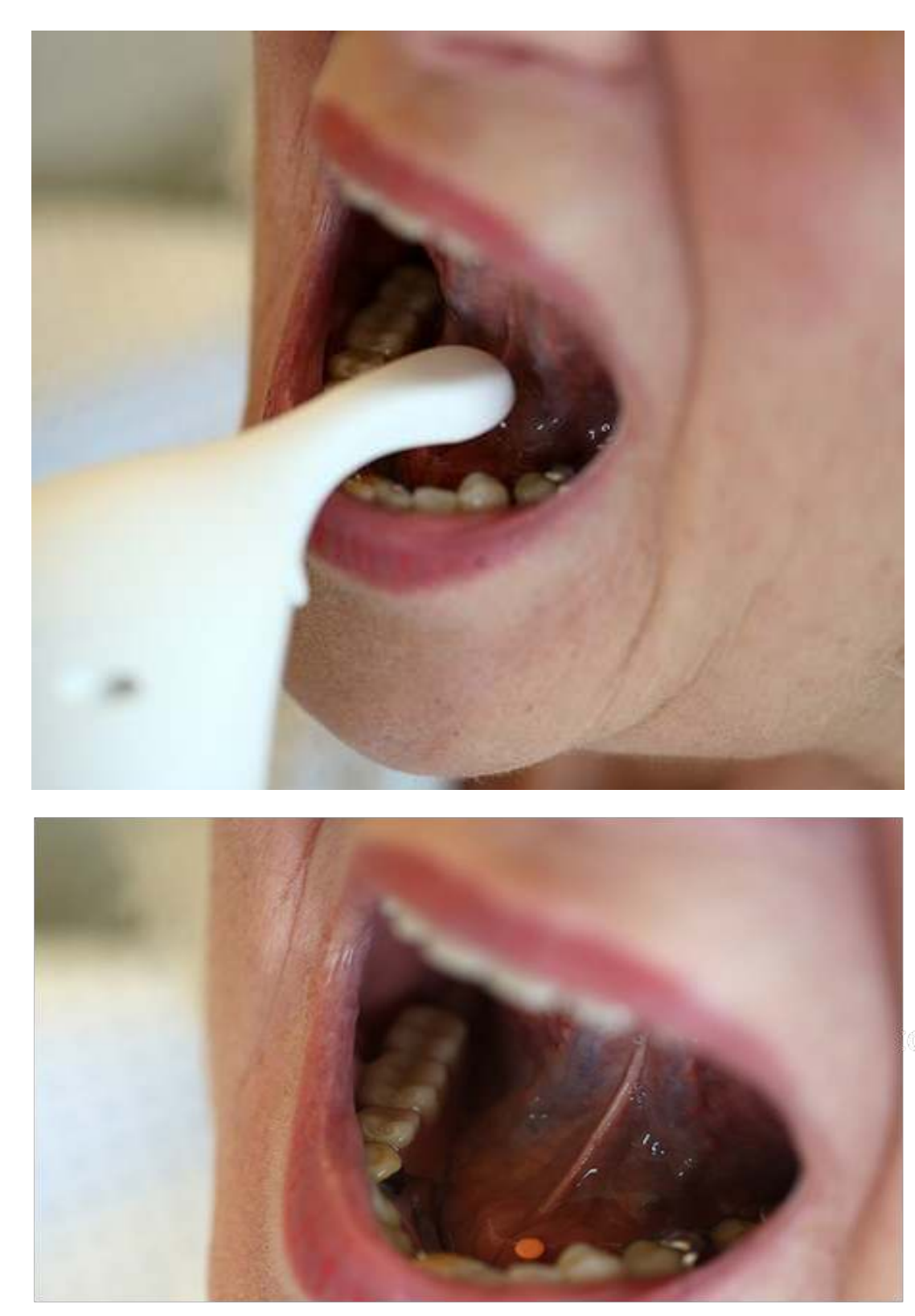

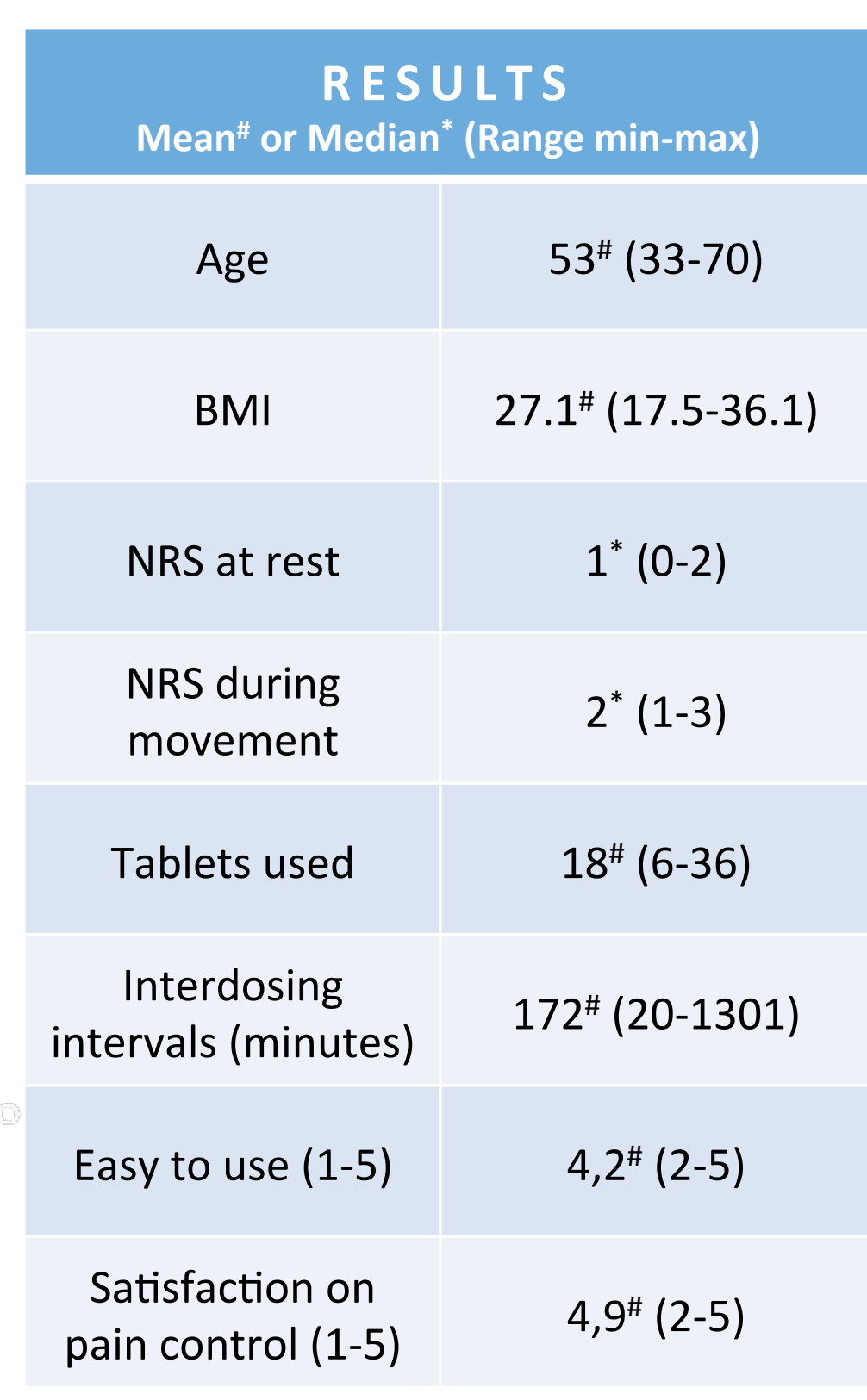

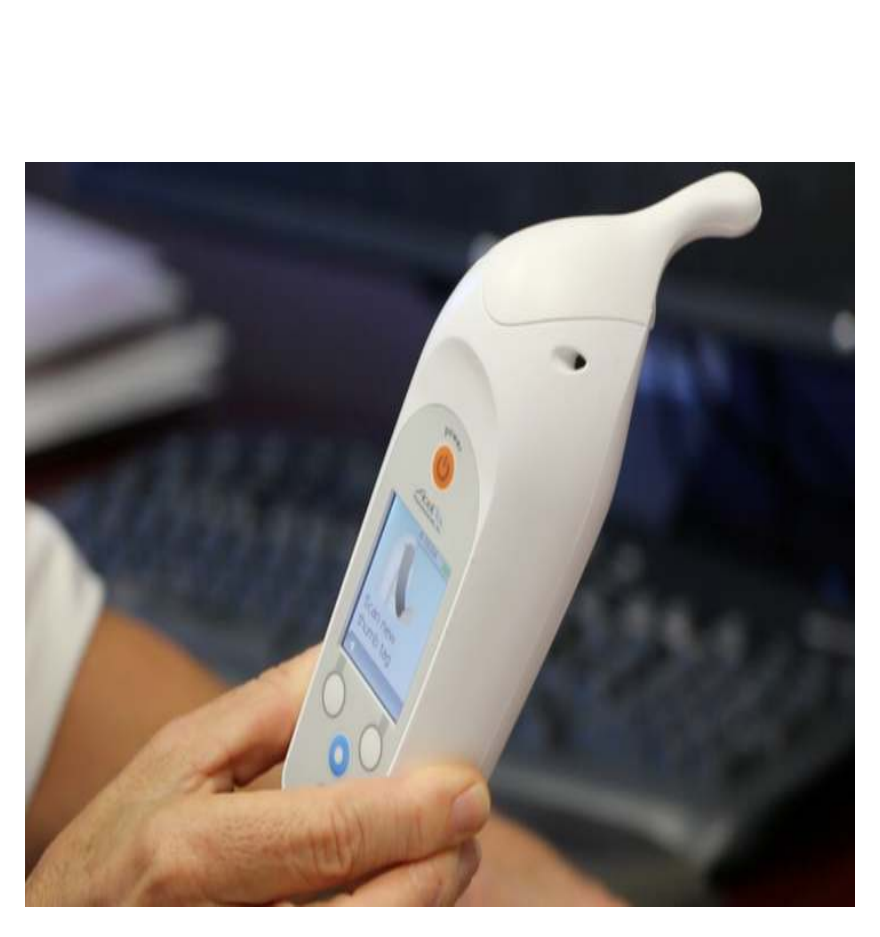

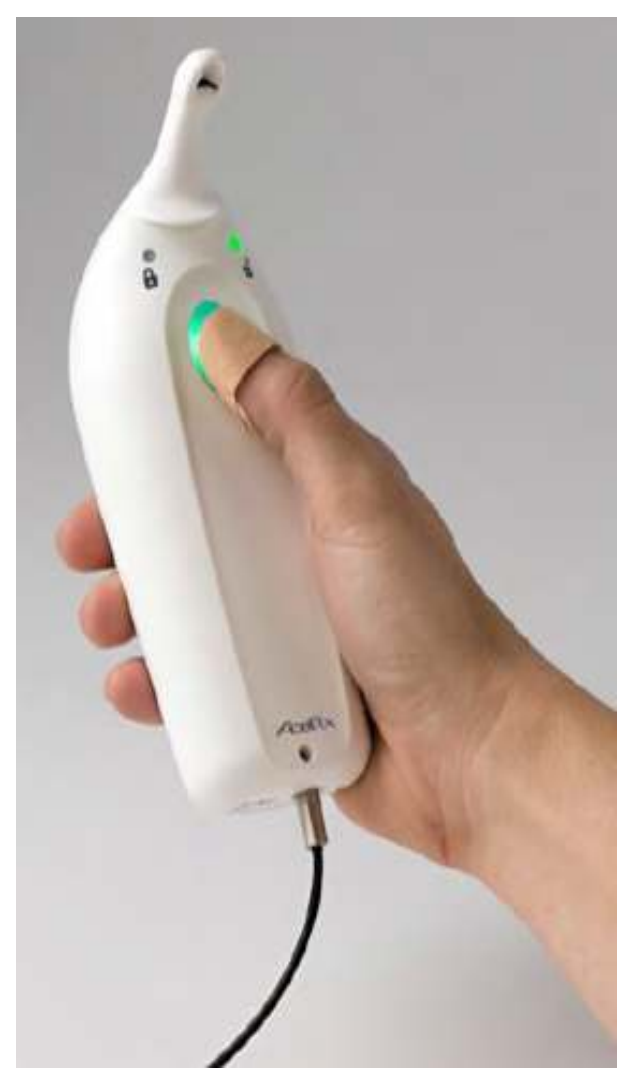

\section{Methods:}

After ethical committee approval we performed an observational case series on 14 patients who underwent TAH under general anesthesia, between October 2017 and April 2018. Sufentanil $0.10-0.20 \mathrm{ng} / \mathrm{ml}$ effect-site concentration was used in induction and maintenance of balanced general anesthesia. PONV prophylaxis was implemented with dexamethasone 4 $\mathrm{mg}$, droperidol $0,625 \mathrm{mg}$ and ondansetron $4 \mathrm{mg}$. Postoperative pain was managed by the exclusive use of SSTS. Efficacy of SSTS was assessed by patient reports of pain intensity on an 11-point numerical rating scale (NRS). Safety assessments included vital signs, and AEs.

\section{Results:}

Average patient age was 53 years, BMI was 27.1. Median NRS was 1 (range 0-2) at rest, and 2 (range 1-3) during movement. Mean number of doses was 18 over 72 hours, with interdosing intervals of 172 minutes. No desaturation $(\mathrm{SpO} 2<92 \%)$ was found. No AEs, including PONV occurred.

\section{Conclusions:}

Intra- and postoperative pain for TAH has been treated effectively and safely with sufentanil as the sole opioid. Interestingly, no PONV has been recorded.

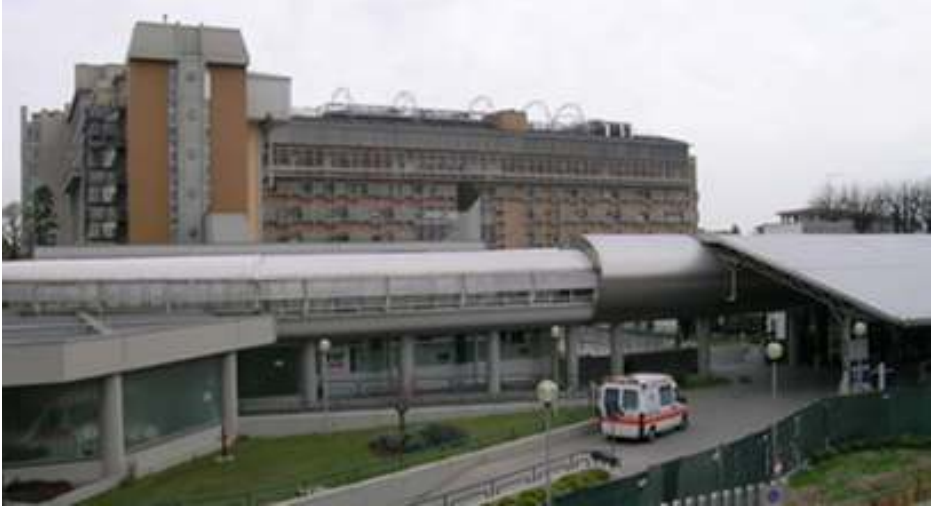

\section{Azienda per l'Assistenza Sanitaria n.5 "FRIULI OCCIDENTALE" Regione Friuli Venezia Giulia}

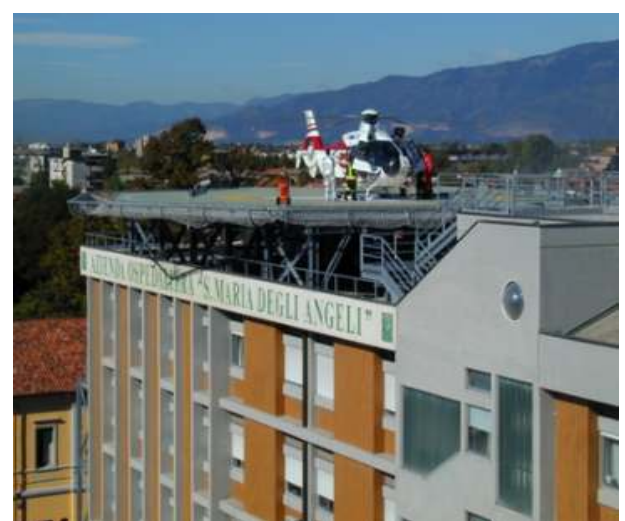

